\title{
Job satisfaction among nurses in a public hospital in Gauteng
}

\author{
"It is all about salaries"
}

\author{
C Selebi, MSc \\ Department of Nursing Education, University of the Witwatersrand.
}

\author{
A Minnaar, PhD \\ Senior Lecturer, Department of Nursing Education, University of the Witwatersrand.
}

Correspondence address:

\section{Dr. A Minnaar}

Department of Nursing Education

School of Therapeutic Sciences

Faculty of Medical Sciences,

University of the Witwatersrand

7 York Street, Parktown, 2193

Tel : (011) 488-3094

Fax :086 5029905

E-mail : minnaarans $@$ therapy.wits.ac.za

\section{Abstract: Curationis 30(3): $x-y$}

Introduction: The nursing profession in South Africa has lost skilled nurses due to intense international recruitment drives. The public hospital in this study has also failed to recruit and retain skilled nurses. The shortage of skilled nurses has led to deterioration in patient nursing care.

The aim of this study: The aim of this study was to describe the level of job satisfaction among nurses in a public hospital.

The methodology: A quantitative, descriptive survey was conducted. The data were collected using the Minnesota Satisfaction Questionnaire. The sample included nurses working in a specific public hospital.

Results: Generally all the nurses experienced low satisfaction $(42 \%)$ with the motivational aspects of their job, such as motivation, responsibility, opportunity for creativity and innovation, independence, and recognition. Nurses also experienced very low levels of satisfaction (22\%) with the hygiene aspects of their job, namely, relationships in the workplace, supervisors' decision-making skills, supervision, working conditions, policies, job security, and salaries.

Conclusions: Health services need to be made aware of the high level of dissatisfaction of nurses. The hospital struggles to keep nurses in their posts, and could benefit from taking note of the results of this study. The findings indicate some of the aspects which need to be considered in a human resource planning strategy for nurses. The hospital and nursing management needs to rethink nurses' salaries, supervision methods and relationships, and also how the Department of Health policies are implemented.

\section{Introduction and background to the problem}

The conditions in public hospitals have reached a crisis level. According to Seshoka (2005: 32), public hospitals are hounded by a dire shortage of nurses, with a reported staffing ratio of one nurse to forty one $(1: 41)$ patients. It was important to address the shortage of nurses and to attend to the nurses' turnover rates. It was also important to find out how satisfied the nurses were with their working environment, and how the satisfaction level could be improved in order to retain nurses in the service. Once skilled and experienced nurses are successfully retained, the quality of service provision might improve. In the year 2000, nearly half a million (500 000) registered nurses in the United States of America chose not to work in the 
profession in which they trained (Zondagh, 2004: 38). It was also found that there is a negative relationship between nurses' staffing levels and poor patient outcome: the higher the staffing level the better the patient outcome and vice versa (Zondagh, 2004: 38).

The South African nursing profession has recently been experiencing a loss of experienced and skilled nurses. The public hospital in this study experienced a loss of experienced and skilled nurses over the last five years at a rate of sixty seven (67) nurses per year. There are currently five hundred and seventy eight (578) nurses working in this hospital. The institution has failed to retain skilled and experienced nurses and therefore there is a need to establish ways of improving the situation. The nursing staff vacancy rate at the hospital is currently twelve percent. The turnover in nurses has contributed to a decreased quality of nursing services in this hospital since there has been an increase in "negative incident" reports regarding patient care issues. One example involved a nurse who negligently failed to prevent and report a break in the continuity in the skin of a patient, resulting in pressure sores. Another case was an incident of negligence in which a nurse failed to record the nursing activity which a patient received. Furthermore, nurses have been taking sick leave for trivial conditions such as backache, as reflected on the medical certificate, without any further investigation by the doctor. It was felt to be important therefore to investigate the problem of job satisfaction among different categories of nurses at a public hospital in Gauteng, South Africa. This study linked motivators (intrinsic factors) and hygiene factors (extrinsic) as described by Herzberg (1971:1-58) to employment satisfaction in nursing.

\section{Research objectives}

The research objectives were as follows:

To describe job satisfaction
among nurses in a public
hospital.
To compare the job satisfaction
levels of professional and sub-
professional nurses in a specific
public hospital.

\section{Research question}

How satisfied are nurses in the hospital and are there any differences in the level of job satisfaction among different categories of nurses?

\section{Conceptual framework}

The two factor theory in career and job satisfaction by Herzberg (1971) was used as the framework for this study. The theory concerns a person's twodimensional need system. It proposes that one is influenced by both motivational and hygiene factors. Motivational factors refer to elements that generate satisfaction from within the individual, such as being innovative and creative in one's job. Motivational factors (intrinsic), as the term implies, are generally involved in motivating employees. These are the determiners of job satisfaction, for example, promotion, provision of more responsibility, being responsible for one's own practice, having the opportunity to do one's job creatively and innovatively, recognition and achievements.

The hygiene or maintenance factors are the determiners of dissatisfaction, for example, relationships in the workplace with one's supervisor and co-workers, the ability of the supervisor, the working conditions, policies, salaries and job security. Hygiene factors are important in the workplace since they predict fairness in the workplace. They must be present for dissatisfaction to be minimized. Their absence will lead to dissatisfaction but their presence does not guarantee satisfaction.

The data collected during the study were arranged and analyzed according to the motivational and hygiene factors in order to diagnose the level of satisfaction in terms of its origin. Herzberg (1971: 58) emphasizes that factors involved in producing job satisfaction are separate and distinct from factors that lead to job dissatisfaction. Meeting the hygiene factors alone will not bring about job satisfaction. At the same time, however, no motivation strategy will be successful unless the hygiene factors are dealt with satisfactorily (Hertzberg 1971: 58).

\section{Population and sampling}

The target population consisted of five hundred and seventy eight (578) nurses in a public hospital in Gauteng Province. This hospital was selected because of its increased turnover of nurses, and increased patient complaints. There were two hundred and fifty one (251) professional nurses, one hundred and twenty (120) staff nurses and two hundred and seven (207) auxiliary nurses.

A sample of two hundred and thirty (230) nurses was selected for this study. The population was stratified according to the different nursing categories, that is, professional and sub-professional nurses (Staff and Auxiliary). The sampling frame was obtained from the hospital's monthly nurses' allocation. The nurses' allocation was used because all nurses working in this hospital are listed in it. The sampling frame itself was arranged in random order. For example, all qualifying nurses from the sampling frame were allocated a number starting from one (1) to five hundred and seventy eight (578). Small pieces of paper with the same numbers written on them were then mixed in a bowl. The papers were drawn from the bowl and the corresponding number in the target population was then included in the study until two hundred and thirty (230) elements from the total population were obtained. All strata were represented proportionally, that is the stratum with more members had more representation in the sample.

\section{Research methodology}

The design for this study was a quantitative, descriptive survey using the Minnesota Satisfaction Questionnaire (Cook, Hepworth, Wall \& Warr 1981:23) as the data collection tool. Since descriptive surveys are designed to gain more information about the characteristics within a particular field of study, such a survey was used in this study to gain insight into the level of job satisfaction in the public hospital. The study was conducted over a period of two years.

\section{The questionnaire}

The Minnesota Satisfaction Questionnaire (Cook et al, 1981:23), which was formulated at the University of Minnesota, is based on human correspondence with the environment at work. The instrument was divided into two sections; Firstly section A contained demographical data, namely gender, age and the position of the respondent in the institution, Secondly, section B had twenty (20) items with a 5 point Likerttype scale ranging from "Very dissatisfied" to "Very satisfied" dealing with motivational and hygiene factors 


\begin{tabular}{|l|l|l|l|l|}
\hline & $\begin{array}{l}\text { Current } \\
\text { numbers }\end{array}$ & $\begin{array}{l}\text { Sample } \\
\text { size }\end{array}$ & $\begin{array}{l}\text { Sample } \\
\text { realization }\end{array}$ & $\begin{array}{l}\text { Percentage } \\
(\mathbf{n}=\mathbf{1 1 7})\end{array}$ \\
\hline Professional nurses & 251 & 100 & 62 & 52,99 \\
\hline Staff nurses \& Auxiliary nurses & 327 & 130 & 55 & 47,00 \\
\hline Total & 578 & 230 & 117 & 50,86 \\
\hline
\end{tabular}

(Cook et al 1981:23). Permission was obtained from the authors to use the instrument, and minor language adjustments were made for the South African context.

In Schriesheim \& Murphy's (1976) study with 54 social workers, the general job satisfaction scale registered a KuderRichardson internal reliability of 0.74 (Cook et al, 1981:23). This study reported a Cronbach alpha of 0.80 and 0.84 for the motivational and hygiene subscales in a study of 170 machinists and technicians.

\section{Validity}

The Minnesota Satisfaction Questionnaire (Cook et al, 1981:23) consists of twenty (20) items that measure job (general) satisfaction. It also consists of sub-scales that measure aspects of motivational and hygiene satisfaction. In the questionnaire the motivational factors are reflected in items $4,5,6,7,10,12,13,14,17,18,19$ and 23 . The hygiene factors are reflected in items $8,9,11,15,16,20,21$ and 22 .

Experts in the field of nursing management and research were asked to reflect on the content and suitability job satisfaction in a public hospital in South Africa. One of those consulted had management expertise of more than ten (10) years with extended knowledge of nursing and nurses' staffing issues. The second expert had an extensive knowledge of research, English language and nursing issues with a good knowledge of questionnaire development. The third expert had extensive knowledge of staffing and nursing issues with twenty years of teaching experience and was in the process of studying for a PhD. The fourth expert had thirty years of clinical experience and was also studying further. This expert had an in-depth knowledge of clinical practice and ethical issues. Some of the questions were open to various interpretations, for example, item 1 read "to keep at all times" and was changed to "being meaningfully occupied with your work at all times". Item 2 read "to work alone" and was changed to "the opportunity to work independently in your work". Item 4 read "the opportunity to be somebody" and was changed to "the opportunity to be seen contributing positively to the society living in your community". Item 10 read "the opportunity to tell other people what to do" and it was changed to "the opportunity to delegate to other people". Item 12 read "the way the policies are implemented" and the statement was changed to "the way that the Gauteng Department of Health policies are applied."

\section{Reliability}

The data in this study were collected by one researcher. Reliability played an important part in the selection of an instrument since it enhances the power of a study to detect significant differences or relationships actually occurring in the population under study (Burns \& Grove 2001 :396). The Cronbach alpha was 0.84 - 0.88 for this study, using the Minnesota Satisfaction Questionnaire.

The questionnaire was piloted at the hospital from 1 June 2005 to 12 June 2005 , utilizing 30 respondents - 10 registered nurses, 10 staff nurses and 10 auxiliary nurses. The nurses who participated in the pilot study were not included in the main study. The purpose of the pilot study was to identify the strengths and weaknesses in the research, that is, the intended design, sample size and data collection instrument and also to check whether the participants understood the questionnaire.

\section{Ethical considerations}

The study was conducted after obtaining ethical clearance from the
University of the Witwatersrand's Committee for Research in Human Subjects. The permission to conduct the study and to have access to the participants was sought from the hospital's Chief Executive Officer and the Deputy Director of Nursing. Further permission was obtained from the Gauteng Department of Health. The participants were protected from harm, deceit, coercion and invasion of privacy, by withholding the names of the participants or any characteristics that might lead to their identification. Informed written consent was obtained from the participants, after explaining the research and allowing them to ask questions. The participants were informed about their right to withdraw from the study as and when they wished.

\section{Data collection}

The respondents were offered the opportunity to ask questions before they participated. The respondents were given questionnaires to fill out during the periods that the researcher visited the hospital and those given the questionnaires were ticked off the sampling frame to avoid duplication. The respondents posted the questionnaires at a central point in the hospital from where they were collected by the researcher. The box was sealed so that nobody else had access to them. Two hundred and thirty respondents were given questionnaires. According to Table 1 , the sampling realization was one hundred and seventeen (117) or $50.86 \%$. Prevalence of satisfaction among nurses for the total group, as well as the subgroups, was reported as a percentage along with the $95 \%$ confidence interval.

\section{Data analysis}

The data were captured on a spreadsheet using Microsoft Excel computer programme and a descriptive analysis was carried out by the researcher using 
the computer statistics programme Moonstats. The data were given to the statistician in the Faculty of Health Sciences at the University of the Witwatersrand to analyze using Microsoft's STATA programme.

Prevalence of satisfaction among nurses for the total group, as well as the subgroups, was reported as a percentage along with the 95\% confidence interval. Subgroups, that is professional and subprofessional (Staff and Auxiliary nurses), were compared for items in the instrument using crosstabulation. Groups were compared with respect to the composite score on the Minnesota Satisfaction instrument using the T-test. Testing was done at 0.05 level of significance.

Figure 1: Job satisfaction for all nurses on the Minnesota Job Satisfaction Questionnaire in percentages $(n=117)$

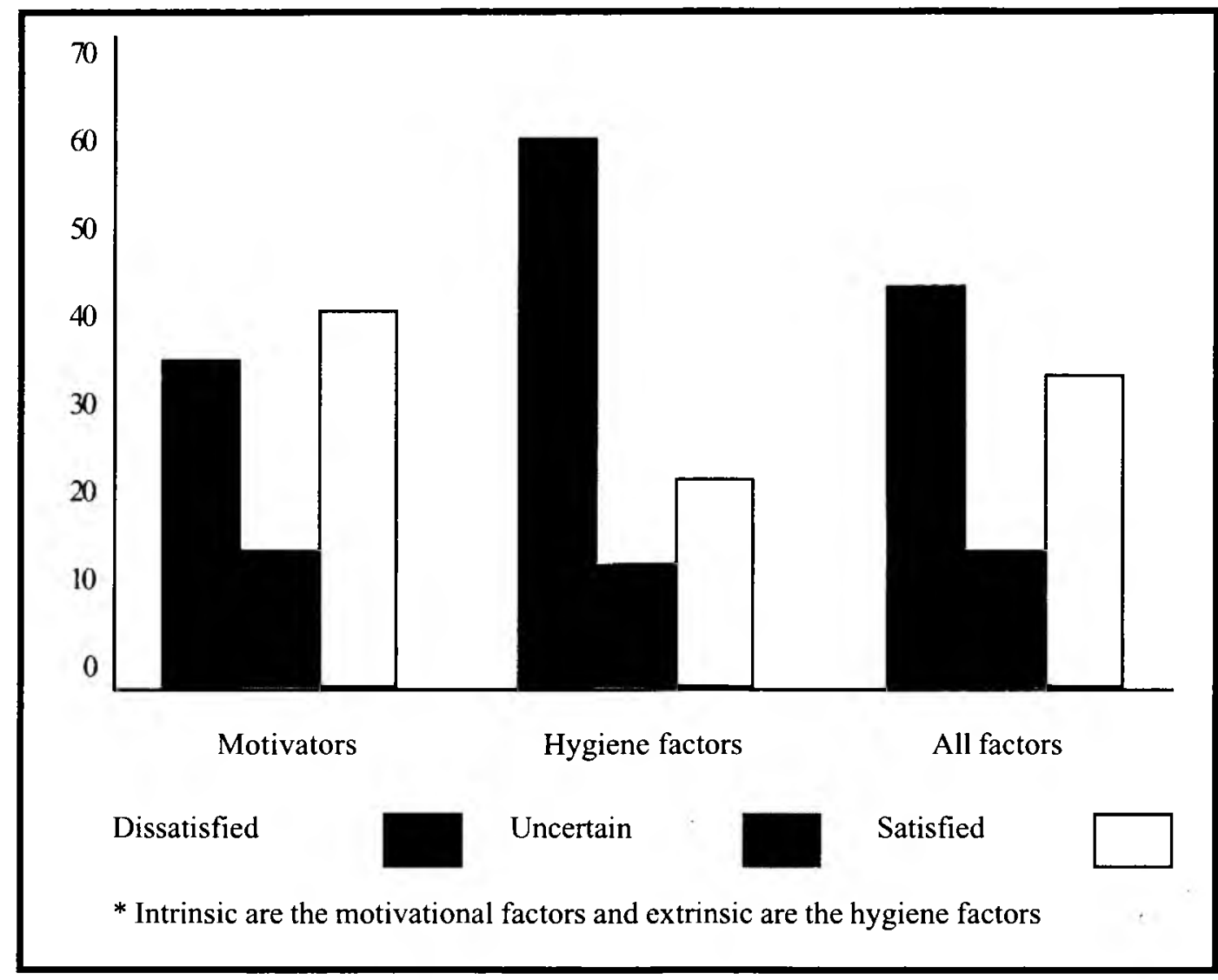

influenced the level of job satisfaction. The majority of respondents were females. Ninety one and a half percent $(91.5 \%)$ of respondents were females. Only eight and a half percent $(8.5 \%)$ were males. From Table 2 it is clear that the majority of respondents $(52.1 \%)$ were in the age group 20-39 years.

\section{Job satisfaction}

The overall job satisfaction of all nurses with their jobs was at a very low level $35 \%$. Nurses experienced low levels of satisfaction and then in terms of the overall job satisfaction of nurses. Factors causing dissatisfaction among nurses in the workplace are then identified and, finally, the level of job satisfaction among the different categories of nurses is compared. For the purpose of this study satisfaction was considered low if $49 \%$ and less, moderate or medium if between 50 and $59 \%$, and high if $60 \%$ and above.

\section{Gender and Age}

Gender was important in this study because the gender of the nurses
$(42 \%)$ with motivational aspects of their job, such as motivation, responsibility, opportunity for creativity and innovation, independence, and recognition. Nurses experienced very low levels of satisfaction $(22 \%)$ with the hygiene aspects of their job, namely, relationships in the workplace, supervisors' decisionmaking skills, supervision, working conditions, policies, job security and compensation, as shown in Figure 1.

\section{Job dissatisfaction}

Nurses did not experience job satisfaction at the public hospital during the two years of the research. In fact nurses were to a large extent dissatisfied with their jobs. The top ten factors causing dissatisfaction among nurses in the public service were identified in this study. According to Figure 2, salaries $(96.58 \%)$ were the main reason. Promotion and career development was the second highest factor resulting in dissatisfaction among nurses at $82.05 \%$. Working conditions $(81.2 \%)$ were listed as the third most important factor and Department of Health policy implementation $(72.64 \%)$ was the fourth major factor causing dissatisfaction among nurses in the public hospital. Other factors which caused dissatisfaction were identified as acknowledgement (or the lack of) from supervisors $(66.67 \%)$, autonomy in the job $(51.28 \%)$, a feeling of accomplishment from doing the job $(49.57 \%)$, the supervisor's decision-making ability $(42.74 \%)$, creativity in the job (43.59\%) and the way supervisors make nurses feel $(42.74 \%)$.

A comparison of satisfaction between professional and sub-professional nurses regarding motivational factors in a public hospital

The findings are discussed according to 
How supervisors make nurses feel

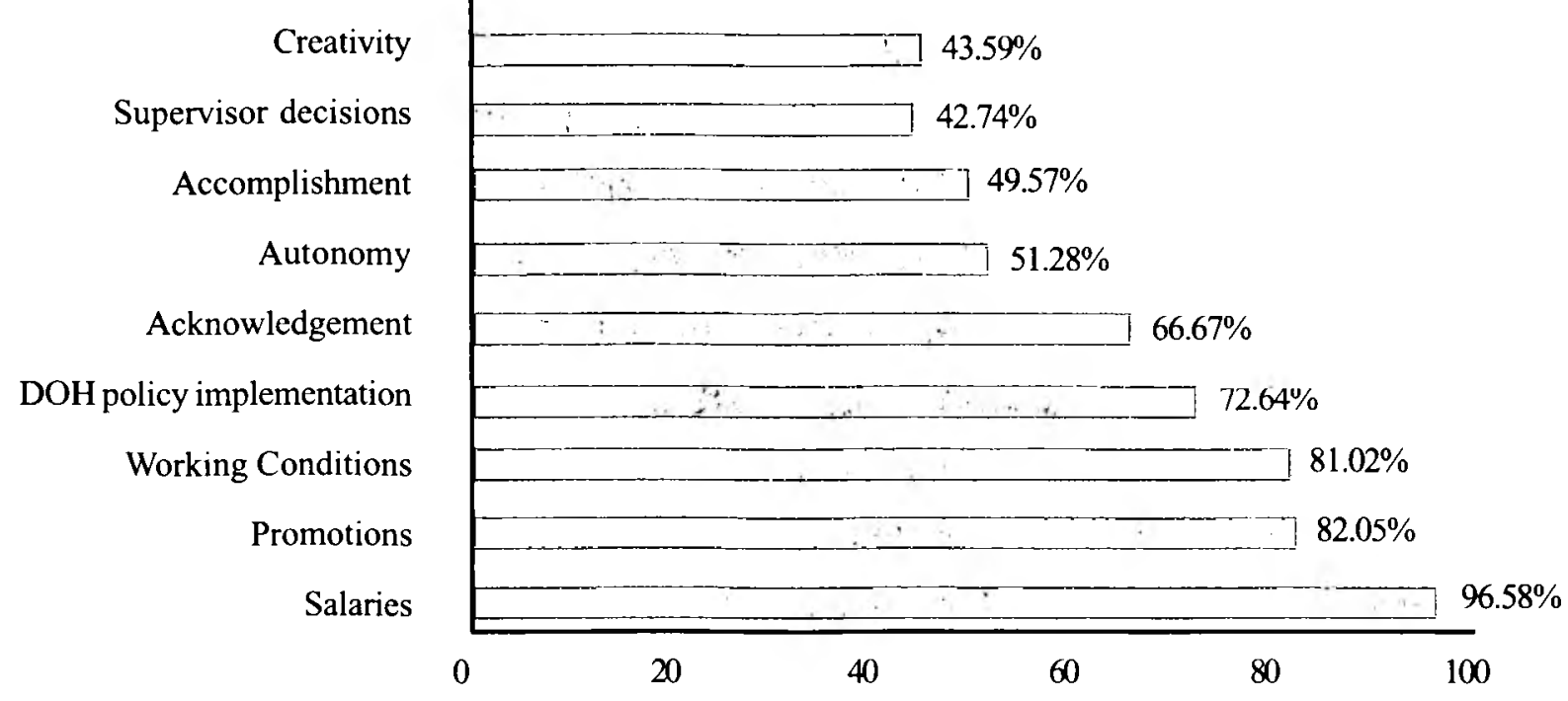

the following sub-headings: working as a nurse, moral/ethical issues, leadership issues, and self-actualization issues.

\section{Working as a nurse}

According to Item 4, being meaningfully occupied with their work, professional nurses indicated low satisfaction $(46.77 \%)$ and the sub- professional group moderate satisfaction (50.91\%). For Item 5 , the opportunity to work independently, the two groups indicated a high level of satisfaction with professional nurses at $66.13 \%$, and sub-professional nurses at $63.64 \%$. Professional nurses demonstrated low satisfaction $(45.16 \%)$ with Item 6 , the opportunity to practise different things from time to time while sub-professional nurses indicated a moderate level of satisfaction $(56.36 \%)$ as shown in Table 3.

\section{Moral/Ethical issues}

A low to moderate satisfaction was expressed by both groups for Item 7 - the opportunity to be seen as contributing positively to the society living in their community (professional nurses $41.94 \%$, and sub-professional nurses $54.55 \%$ ). Nurses demonstrated high satisfaction levels with Item 12 , the way in which they take care of other people $-72.58 \%$ of professional nurses and $80 \%$ of subprofessional nurses. For Item 10, doing things that go against their conscience, the professional nurses had a low satisfaction level $(33.87 \%)$ and subprofessional nurses demonstrated an even lower level $(18.18 \%)$ which was statistically significant with a p-value of 0.05 as shown in Table 3.

\section{Leadership aspects}

As expected, the sub-professional nurses $(41.82 \%)$ demonstrated lower satisfaction than the professional group $(67.74 \%)$ with the opportunity to delegate to others (Item 13) with a p-value of 0.02 , since it is not within the sub-professional nurse's position to delegate. The subprofessional nurses demonstrated a low satisfaction $(43.64 \%)$ and the professional nurses a high satisfaction $(67.74 \%)$ with the opportunity to apply their knowledge and skills (Item 14) which had a statistically significant difference with a p-value of 0.002 mainly because the sub-professional nurses carried out orders given by the professional group while the latter had to plan and coordinate the nursing practice in the units to ensure outputs were achieved (see Table 3).

\section{Self-actualization and promotional issues}

It was significant to note that both groups experienced very low levels of satisfaction with the opportunity for promotion and advancement in their workplace (Item 17) - 6.45\% for professional nurses and $7.27 \%$ for subprofessional nurses. This was the lowest level of satisfaction for both groups. Further investigation is needed in order to establish the degree of this perception among nurses employed by the Gauteng
Department of Health. The subprofessional nurses demonstrated a low level of satisfaction $(16.36 \%)$ as did the professional nurses $(35.48 \%)$ with the freedom to use their own judgement in the workplace (Item 18). There was a significant statistical difference between the two groups with a p-value of 0.02 . The professional group has to rely more on their own judgement while sub-groups make observations which they report to the professionals for judgement. Nevertheless, both make judgements irrespective of the differing level. It was puzzling that professional nurses felt they were not able to apply their judgement. Both groups demonstrated a low satisfaction with the opportunity to be innovative and creative in their work (Item 19), 35.4\% of professional nurses and $27.27 \%$ of sub-professional nurses. The feeling of accomplishment they get from their work (Item 23) also showed low levels of satisfaction, at $35.48 \%$ for the professional nurses, and $23.64 \%$ for the sub-professional nurses (see Table 3).

\section{A comparison of} satisfaction between the professional and subprofessional nurses regarding the hygiene
factors in a public hospital

The following observations were drawn from the hygiene factors regarding job satisfaction as shown in Table 4 below. They are discussed under the following 
Table 3 : A comparison of satisfaction between Professional $(p / n)$ and Sub-professional (sub. P/n) nurses regarding the motivating factors (intrinsic) in a specific hospital ( $n=117)$. (Items $4,5,6,7,10,12,13,14,17$, 18,19 , and 23)

\begin{tabular}{|c|c|c|c|c|c|}
\hline IIEM & Categories & Dissatisfied \% & Uncertain \% & Satisfied $\%$ & \begin{tabular}{|l} 
p-value for T- \\
test
\end{tabular} \\
\hline \multirow{2}{*}{$\begin{array}{l}\text { 4. Bcing able to be meaningfully } \\
\text { occupied with you work at all } \\
\text { times }\end{array}$} & $\mathrm{P} / \mathrm{N}$ & 38.71 & 14.52 & 46.77 & \multirow[t]{2}{*}{0.29} \\
\hline & Sub-P/N & 25.45 & 23.64 & 50.91 & \\
\hline \multirow{2}{*}{$\begin{array}{l}\text { 5. The opportunity to work } \\
\text { independently in your work. }\end{array}$} & $\mathrm{P} / \mathrm{N}$ & 20.97 & 12.9 & 66.13 & \multirow[t]{2}{*}{0.98} \\
\hline & Sub-P/N & 18.18 & 18.18 & 63.64 & \\
\hline \multirow{2}{*}{$\begin{array}{l}\text { 6. The opportunity to practise } \\
\text { different things from time to time. }\end{array}$} & $\mathrm{P} / \mathrm{N}$ & 41.94 & 12.9 & 45.16 & \multirow[t]{2}{*}{0.29} \\
\hline & Sub-P/N & 34.55 & 9.09 & 56.36 & \\
\hline \multirow{2}{*}{$\begin{array}{l}\text { 7. The opportunity to be seen as } \\
\text { contributing positively to the } \\
\text { society living in your community. }\end{array}$} & $\mathrm{P} / \mathrm{N}$ & 35.48 & 22.58 & 41.94 & \multirow[t]{2}{*}{0.25} \\
\hline & Sub-P/N & 29.09 & 16.36 & 54.55 & \\
\hline \multirow{2}{*}{$\begin{array}{l}\text { 10. Doing things that don't go } \\
\text { against your conscience. }\end{array}$} & $\mathrm{P} / \mathrm{N}$ & 38.71 & 27.42 & 33.87 & \multirow[t]{2}{*}{$0.05^{*}$} \\
\hline & Sub-P/N & 52.73 & 29.09 & 18.18 & \\
\hline \multirow{2}{*}{$\begin{array}{l}\text { 12. The way in which you take } \\
\text { care of other people. }\end{array}$} & $\mathrm{P} / \mathrm{N}$ & 12.9 & 14.52 & 72.58 & \multirow[t]{2}{*}{0.77} \\
\hline & Sub-P/N & 16.36 & 3.64 & 80.00 & \\
\hline \multirow{2}{*}{$\begin{array}{l}\text { 13. The opportunity to delegate } \\
\text { to other people. }\end{array}$} & $\mathrm{P} / \mathrm{N}$ & 24.19 & 8.06 & 67.74 & \multirow[t]{2}{*}{$0.02^{*}$} \\
\hline & Sub-P/N & 36.36 & 21.82 & 41.82 & \\
\hline \multirow{2}{*}{$\begin{array}{l}\text { 14. The opportunity to apply } \\
\text { your knowledge and skills. }\end{array}$} & $\mathrm{P} / \mathrm{N}$ & 20.97 & 11.29 & 67.74 & \multirow[t]{2}{*}{$0.002^{*}$} \\
\hline & Sub-P/N & 49.09 & 7.27 & 43.64 & \\
\hline \multirow{2}{*}{$\begin{array}{l}\text { 17. The opportunity for } \\
\text { promotion and advancement in } \\
\text { your work. }\end{array}$} & $\mathrm{P} / \mathrm{N}$ & 82.26 & 11.29 & 6.45 & \multirow[t]{2}{*}{0.91} \\
\hline & Sub-P/N & 81.82 & 10.91 & 7.27 & \\
\hline \multirow{2}{*}{$\begin{array}{l}\text { 18. The freedom to use your own } \\
\text { judgement in the workplace. }\end{array}$} & $\mathrm{P} / \mathrm{N}$ & 43.55 & 20.97 & 35.48 & \multirow[t]{2}{*}{$0.02^{*}$} \\
\hline & Sub-P/N & 60 & 23.64 & 16.36 & \\
\hline \multirow{2}{*}{$\begin{array}{l}\text { 19. The opportunity to be } \\
\text { innovative and creative in your } \\
\text { work. }\end{array}$} & $\mathrm{P} / \mathrm{N}$ & 41.94 & 22.58 & 35.4 & \multirow[t]{2}{*}{0.46} \\
\hline & Sub-P/N & 45.45 & 27.27 & 27.27 & \\
\hline \multirow{2}{*}{$\begin{array}{l}23 . \quad \text { The feeling of } \\
\text { accomplishment you get from } \\
\text { your work. }\end{array}$} & $\mathrm{P} / \mathrm{N}$ & 43.55 & 20.97 & 35.48 & \multirow[t]{2}{*}{0.13} \\
\hline & Sub-P/N & 56.36 & 20 & 23.64 & \\
\hline
\end{tabular}

* p-value for the T-test is significant at 0.05 
sub-headings: supervision, policies, job security and salary, and relationships/ social issues.

\section{Supervisory issues}

The sub-professional nurses $(32.73 \%)$ expressed a lower satisfaction level than professional nurses $(43.55 \%)$ ) regarding the way their supervisors handle them (Item 8). The reason for the difference in perceptions needs further exploration. It was disturbing that both groups demonstrated a low level of satisfaction with the ability of their supervisors to take/make decisions (Item 9) - 32.36\% for professional nurses and $27.27 \%$ for subprofessional nurses (see Table 4).

\section{Policy issues}

Both professional (14.52\%) and subprofessional nurses $(12.73 \%)$ expressed low levels of satisfaction with the way the Gauteng Department of Health policies are put into practice (Item 15).

\section{Salary and job security issues}

A very low satisfaction level was experienced by both professional (1.61\%) and sub-professional nurses $(1.82 \%)$ with their salary compared to the work they do (Item 16). 11.29\% of professional and $12.73 \%$ of sub-professional nurses also indicated low satisfaction for Item 20 regarding their working conditions (see Table 4).

Sub-professional nurses indicated a lower satisfaction $(36.36 \%)$ than professional nurses $(61.29 \%)$ with the way their employment is guaranteed (Item 11), which is puzzling because the guarantee of employment is not related to one's position. The Basic Conditions of Employment Act No. 75 of 1977 covers all employees irrespective of position unless a nurse loses his or her job through being de-registered by the South African Nursing Council for nurses' acts or omissions. It would be worth exploring why the sub-professional group feel their jobs are not guaranteed. The level was significantly different with a $\mathrm{p}$-value of 0.014 .

\section{Relationships with other staff members and social}

\section{issues}

According to Table 4, professional nurses were moderately satisfied
$(58.06 \%)$ with the way their co-workers get along with one another. However, sub-professional nurses demonstrated low satisfaction $(43.64 \%)$ with the way that their co-workers get along with one another (Item 21). Both groups expressed low satisfaction with the compliments and/or acknowledgement they get from doing their job (Item 22) with $12.9 \%$ for professional nurses and $29.09 \%$ for subprofessional, since this requires no special resources but simply an oral acknowledgement such as "That was a job well done, keep it up."

\section{Discussion, Conclusions and Recommendations}

On the whole the satisfaction of nurses was very low and this is an alarming fact for the health services in Gauteng and in South Africa. The motivational aspects of their job with which nurses did express satisfaction were the opportunity to work independently, the opportunity to practise different things from time to time, the way in which they take care of other people, and the opportunity to delegate.

Nurses demonstrated low levels of satisfaction with hygiene aspects of their jobs such as praise from supervisors and/ or the acknowledgement they get for doing their job, the way policies are implemented, their salary compared to the work that they perform, the opportunity for promotion and advancement, and working conditions. Nurses expressed satisfaction with only one hygiene factor, namely, the way that their co-workers get along with one another.

The health services need to be made aware of these low levels of satisfaction among nurses regarding the hygiene aspects of their jobs. Public hospitals struggle to keep nurses in their posts, and could benefit from taking note of the results of this study. This particular public hospital needs to rethink its supervision methods and the relationships between supervisors and nurses, and also the way in which it implements Department of Health policies. There should be a partnership between community representatives, nursing personnel, nursing leaders, and policymakers. If this hospital intends to retain nurses, very serious attention needs to be given to the needs of nurses regarding salaries, workload, and working conditions, as well as to the recognition of nurses for their contribution. An in-depth study on why nurses do not get a sense of accomplishment from their work needs to be carried out in order to establish what can be done to improve the level of satisfaction. Further research on why nurses feel that there is no opportunity for promotion and advancement in their current jobs (Item 17) also needs to be conducted.

Overall, all nurses experienced very low levels of satisfaction (35\%) for all the factors regarding the work environment in the public hospital. Job satisfaction cannot be achieved until the hygiene factors are satisfactory, including working conditions, policy implementation, equitable salaries, appreciation in the workplace, supervision and the ability. of supervisors. Once the hygiene factors are in place, then the employer can focus on heightening the motivational factors affecting nurses, such as the opportunity to work independently, to practise different things from time to time, to delegate to others, to apply their knowledge and skills, opportunities for promotion and advancement, freedom to use their own judgement, and to be innovative and creative. A feeling of accomplishment in their work will then follow.

The retention of employees is one of the biggest challenges for every nursing service manager today in South Africa. To retain nurses successfully requires an organisational culture that inspires loyalty and commitment. Supervisors and managers must be made accountable for the retention of nurses, especially as it has been shown that the relationship between the nurse and the supervisor determines $59 \%$ of job satisfaction (Neuhauser 2002:470). Much is being done at the moment to recruit nurses into the nursing profession, but once the health services have them, the current problem in public hospitals in South Africa is how to keep them.

As illustrated in this study, it is not only money that would keep nurses, but also career prospects, the behaviour of supervisors, relationships with others and patient care. In general nurses will stay because they are respected and feel pride in their work. We as nurses need to build hospital environments that offer more than satisfaction, that inspire employees to have pride in their work. Nurse managers need to ensure that the hospital is generally a distinctly better 
Table 4: A comparison of satisfaction between Professional $(\mathrm{p} / \mathrm{n})$ and Sub-professional (sub. P/n) nurses regarding the hygiene factors (extrinsic) in a specific hospital (items $8,9,11,15,16,20,21$ and 22)

\begin{tabular}{|l|l|l|l|l|l|}
\hline \multirow{2}{*}{ IIEM } & Categories & Dissatisfied \% & Uncertain \% & Satisfied \% & p-value for T- \\
test
\end{tabular}

* p-value for the T-test is significant at 0.05

place to work (Neuhauser 2002:470).

Special retention plans for top performing nurses should be developed to ensure they stay on in the employment of the hospital. Nurse managers should work individually with top performers to build their careers around their personal interests. Nurse supervisors need to identify the top performers in a hospital and ask what will keep them. The focus must be on an inspiring culture which will ensure that top performers stay and produce quality clinical care with the highest level of patient satisfaction.

Furthermore, it is clear that nurses in this study want better salaries, better promotion opportunities, more flexibility in policy implementation, more autonomy, more praise for a job done well, and recognition for clinical excellence. They want supervisors to make them feel good. Nurse managers should encourage and reward nurses who build relationships with other staff members. Quality care could be enhanced by good coaching, teaching and mentoring of employees. The first-line supervisor can make or break the hospital. Supervisors need to know how to treat their nurses, in the same way as they know how to treat their patients. Supervisors should be trained in coaching, mentoring and teaching skills and receive follow-up support after training. They should also be encouraged to reflect on the difficulties of their supervisory role. Listening skills are extremely important in hospital management. Ask nurses what they need and the answers may be surprising (Neuhauser 2002:472-478).

Lastly, the role of trade unions needs to be clarified in a situation where nurses are experiencing a very low level of job satisfaction. Nurse managers and hospital management are in negotiation with trade unions regarding conditions of service and salaries for nurses.

The role of the trade union in taking care of the nurses and their well-being needs to be considered carefully (Swanepoel, Erasmus, Van Wyk, and Schenk 2003:180187). In addition, the question of why nurses are so seriously underpaid needs to be addressed.

\section{References}

BURNS, N \& GROVE, SK 2001: The practice of nursing research conduct critique and utilization. $4^{\text {th }}$ ed. Philadelpia: W. B. Saunders. 
COOK, JD; HEPWORTH, SJ; WALL, TB \& WARR, PB 1981: The experience of work: A compendium and review of 249 measures and their use. London: Academia Press.

ERASMUS, B; SCHENT, H; SWANEPOEL, B \& VAN WYK, M 2003: South African human resource management theory and practice. $3^{\text {rd }}$ ed. Cape Town: Juta.

GILLIES, DA 2002: Nursing Management: A Systems Approach. $3^{\text {rd }}$ ed. Philadelphia: W.B. Saunders Company.

HERZBERG, F 1971: Work and the nature of man. $5^{\text {th }}$ ed. New York: The World publishing company.

JOHNSON, C 2000: Capturing turnover costs. HR Magazine, 7: 107-109.

MASLOW, AH 1954: Motivation and personality. Harper and Brothers.

NEUHUASER, PC 2002: Building a high retention culture in health care. Journal of Nursing Administration, 32 (9): 470478.

SESHOKA, L 2005: Conditions reach crisis level in public hospitals. Nursing Update, 29(3): 32.

SOUTH AFRICA 1977: Act to outline Basic Conditions of Employment. Pretoria: Government Printer. (Act 75 of 1977: Basic Condition of Employment Act, 1977 [as amended]).

SWANEPOEL, B; ERASMUS, B; VAN WYK, M \& SCHENK, H 2003: South African Human Resource Management. Theory and practice. $3^{\text {rd }}$ ed. Cape Town: Juta.

ZONDAGH, C 2004: Safe and adequate nurse staffing. Nursing Update, 29 (3):3842. 